\title{
Measures of the vibration function pass in the wall element diagnostic test
}

\author{
Daniel Lubos ${ }^{1}$, and Mariusz Żółtowski ${ }^{2, *}$ \\ ${ }^{1}$ University of Zilina, Faculty of Civil Engineering, Slovakia \\ ${ }^{2}$ UTP University of Science and Technology in Bydgoszcz, Faculty of Management, Poland
}

\begin{abstract}
Building constructions as well as their constituent structural elements must meet the strength requirements, which will not jeopardize the safety of their use. As part of the research experiment, the focus was on the issue related to strength testing properties of masonry elements using a non-invasive test method involving the measurement of vibrations. 40 samples of bricks. Half of them were deliberately damaged so that it would be possible to assess the suitability of the measurement method used and its variability resulting from damage to the masonry element.
\end{abstract}

\section{Introduction}

Modal analysis is widely used in removing defects caused by infrastructure vibrations, structure modification, updating of the analytical model, or state control, and is also used to monitor the vibrations of structures in the aviation industry and land engineering mechanics $[2,5,3]$.

The vibration test of building structures is not only to the measurement of the vibrations we are interested in. In order for researchers to be able to obtain interesting measurement values (such as the FRF function, stabilization diagrams and accompanying vibration estimators), it is necessary to carry out a whole sequence of operations, which results in the possibility of obtaining interesting data and results.

As part of this study, the methodology of investigations of masonry elements and course of conduct in order to obtain reliable results of conducted vibration tests were described. It was used to describe this process an example of the use of experimental modal analysis in the study of brick elements.

Traditional experimental modal analysis (EAM) uses input (excitation) and output (response) and measures it to estimate modal parameters, consisting of modal frequencies, attenuation and vibrations. However, traditional EAM has some limitations, such as $[1,6,8]$ :

- in traditional EAM, artificial excitation is normally carried out to measure the vibration frequency;

- traditional EAM is usually carried out in a laboratory environment, but in many cases the true state of degradation may differ significantly from those tested in a laboratory environment.

This article presents the results of testing a brick masonry element in a dry environment using experimental modal analysis and appropriate software (partly authoring) used to carry out and visualize the results of such research.

\section{Building structure dynamics}

One of the basic criteria used in the design of modern building structures are the dynamic properties of the structure. They have a direct impact on system vibrations, noise emitted,

\footnotetext{
${ }^{*}$ Corresponding author: mazolto@utp.edu.pl
} 
fatigue strength and structural stability. Analyzes of dynamic properties in most cases encountered in practice are made based on analysis of the behavior of the conglomerate model $[4,7,10]$.

In most cases structural models (MES) are used to describe the dynamics of the structure, which consists in discretization of the system with a continuous distribution of parameters with the adoption of some simplifying assumptions, eg. related to the deflection line of the modeled element (transfer method). However, the models built in this way, for the purposes of dynamics analysis, give approximate results, the use of which is very limited. They require tuning based on the knowledge of properties measured on the actual object.

The use of vibrations in the study of the degradation (quality) of building structures results from the following reasons:

- vibration processes reflect physical phenomena occurring in constructions (deformations, stresses, cracks), on which the degree of destruction (fitness) and proper functioning depend, which results from the nature of the vibration process spreading;

- easy measurement of vibration processes in conditions of normal operation of the facility, without having to turn it off and special preparation, it enables a non-removal assessment of the state of destruction;

- vibration processes are characterized by high speed of information transfer in a time unit, defined by the Shanon formula:

$$
C=F \lg _{2}\left(1+\frac{N_{S}}{N_{Z}}\right)
$$

- depending on the spectral width of the process $\mathrm{F}$ and the ratio of the power of the useful signal NS to the power of interference noise NZ;

- vibration processes are characterized by a complex time, amplitude and frequency structure, which ensures proper evaluation of the state of the entire structure as well as its individual elements.

During the operation of the structure, due to the existence of a number of external factors (extortion of the environment, extortion from other structures) and internal (aging, wear, cooperation of elements) in the structure there are disturbances of equilibrium states which propagate in the elastic medium - the material from which the structure is built. The disorder is dynamic and maintains the conditions of balance between the state of inertia, elasticity, damping and extortion. This results in the dissipation of wave energy, their deflections, reflections and mutual overlap. The existence of sources and the spread of disturbances causes the occurrence of vibrations of the construction elements and the surrounding environment.

When separating the input processes, structure and output processes in the analysis of the dynamic state of the structure, one should remember about their random character.

The internal input, treated as a set of forcing quantities - defining the structure (shape, quality, clearance, etc.) and the method of elements cooperation is shaped in random conditions during production, which is revealed by random properties during operation.

External input, defining the conditions of cooperation of structural elements with other elements of the system (load changes, speed, environmental impact) is in practice also random.

The richness of the possibility of randomness and the existence of disturbances is the reason for additional assumptions about the inputs and the transformations of the structure destruction states. They refer to assumptions about linearity, stationarity and ergodicity of objects models and processes $[6,8,9]$. 


\section{Measuring software}

The latest measurement equipment purchased from SignalLab cooperation named Sigview was used to measure the time of force and response of the system as well as to determine the FRF function. This software allows you to easily perform modal analysis of brick elements, as well as any other building constructions - fig.1.

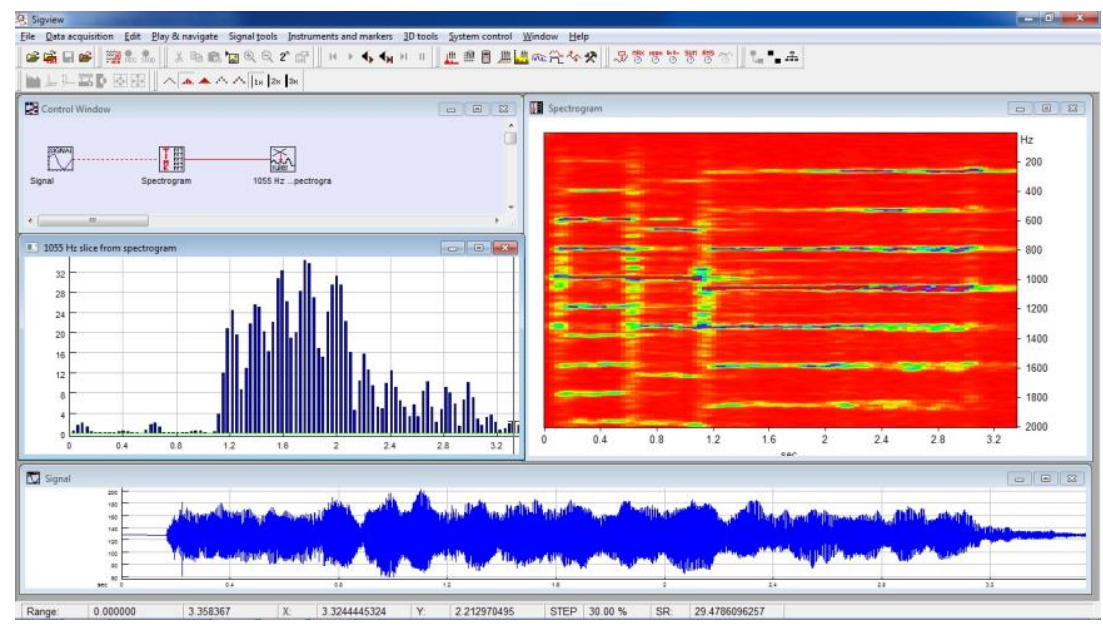

Fig. 1. Sigview interface.

In the measurement system, all the data needed to be calibrate, and the measuring path have been defined. For the needs of research carried out in this stage, it was started by defining the number of active measuring channels. Their number is limited only by the number of inputs on the measurement card, which is different for different models of measurement segments.

Two measurement channels were defined for the measurement using experimental modal analysis. According to the theoretical assumptions of the experimental modal analysis, the first sensor was reserved for a modal hammer (vibration excitation), and in place of 2 piezoelectric sensor was connected to measure the element's response to extortion - Fig.2.

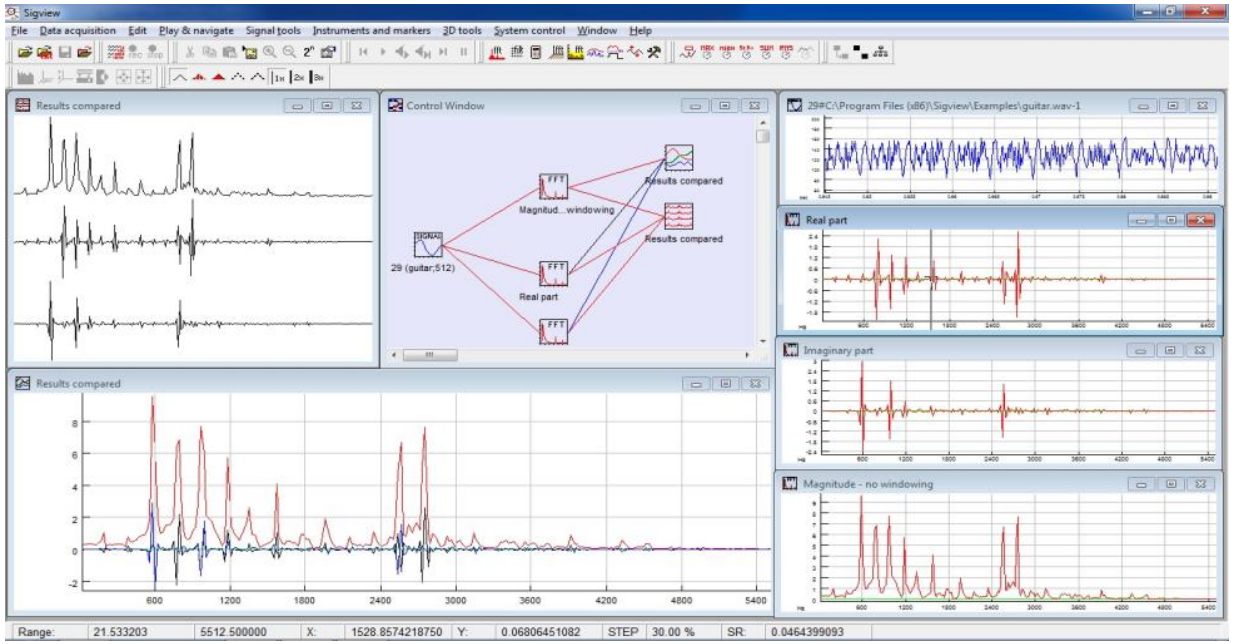

Fig. 2. Calibration of the sensors. 
As part of the examinations that served to describe the course of investigation during the research, brick wall elements were examined - Fig.3. In the implementation of this kind of experiment, experimental modal analysis was used for measurements. For this purpose, 40 bricks were tested, out of which 20 samples were damaged intentionally, to show differences in the obtained test results, which demonstrates the suitability of a given test method for assessing masonry component degradation.
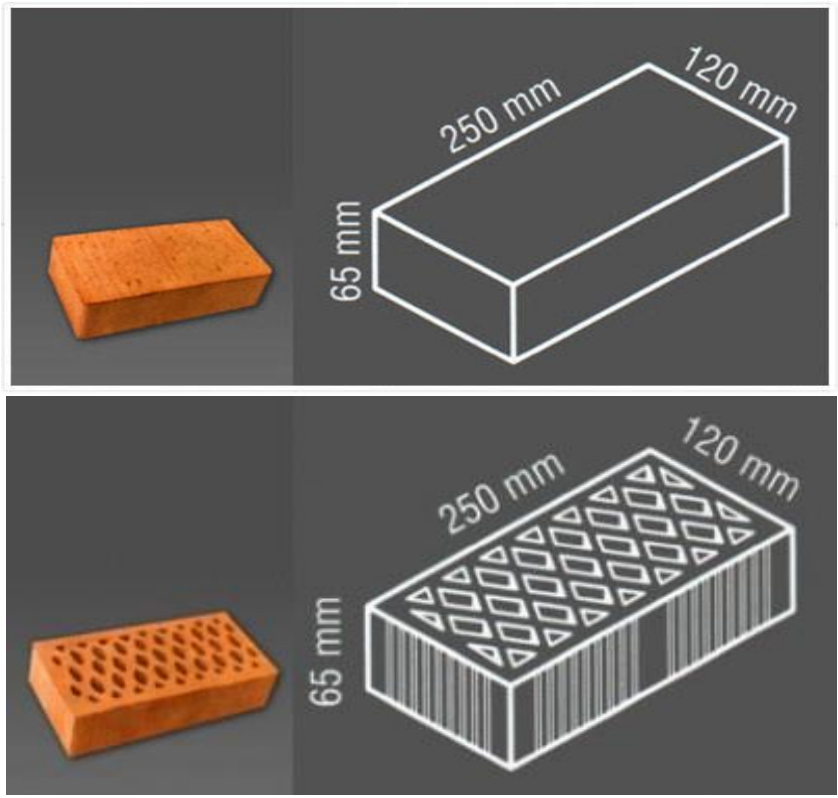

Fig. 3. View of samples subjected to measurements.

After calibrating the measurement system, it was possible to start measurements. According to the assumptions of the modal analysis, the samples were suspended on an unstretchable line, which allowed to release all ties. Tests carried out only in the $\mathrm{Z}$ axis, because since they were brick masonry elements, it is interesting to pass the vibration signal in the direction of the compressive forces acting on the wall. During the measurement, the vibrations were forced by a modal hammer in the $-Z$ direction, while the reception took place in the $+Z$ axis due to the sticky sensor at the bottom of the element. As a result of the conducted tests, the time of force of forced force (modal hammer) and time courses of response (piezoelectric sensor) were obtained, and their visualizations are shown below in Fig.4.

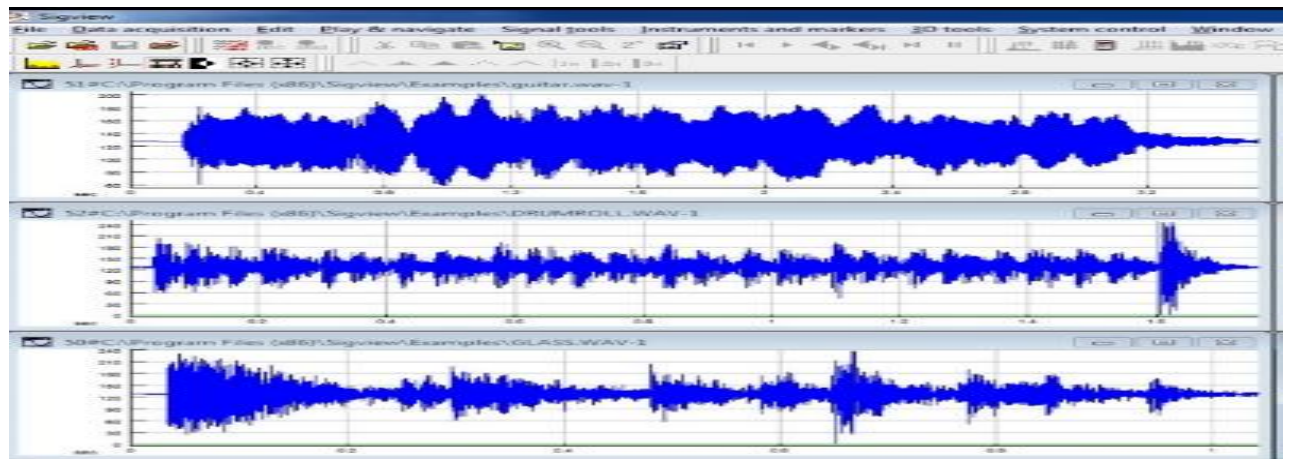

Fig. 4. View during measurement registration in Sigview software. 


\section{Methodology of data acqusition in the form of frf functions generation and calculation of it's surface area}

After recording the time courses of force and response, these results should be subjected to further transformation. The aim of these operations is to obtain the FRF transition function and later to create stabilization diagrams on its basis, thanks to which it is possible to generate the natural frequency of the material being tested. The course of action is described in detail below to obtain the results that are interesting for the researcher. Two new programs operating in the MATLAB environment have been developed for further data processing.

During the vibration tests, the possibilities of acquiring new cognitive values, which may be useful to assess the destruction of the tested wall elements, were analyzed. Such information, apart from time and force transitions and stabilization diagrams together with the generated natural frequencies of the tested elements, may carry the numerical value of the surface area of the obtained signal transition function by the element being tested. To be able to calculate the area under the function curves, a new proprietary software named FUNCTIONS ANALYSIS was created. The program interface view is shown in the figure below.

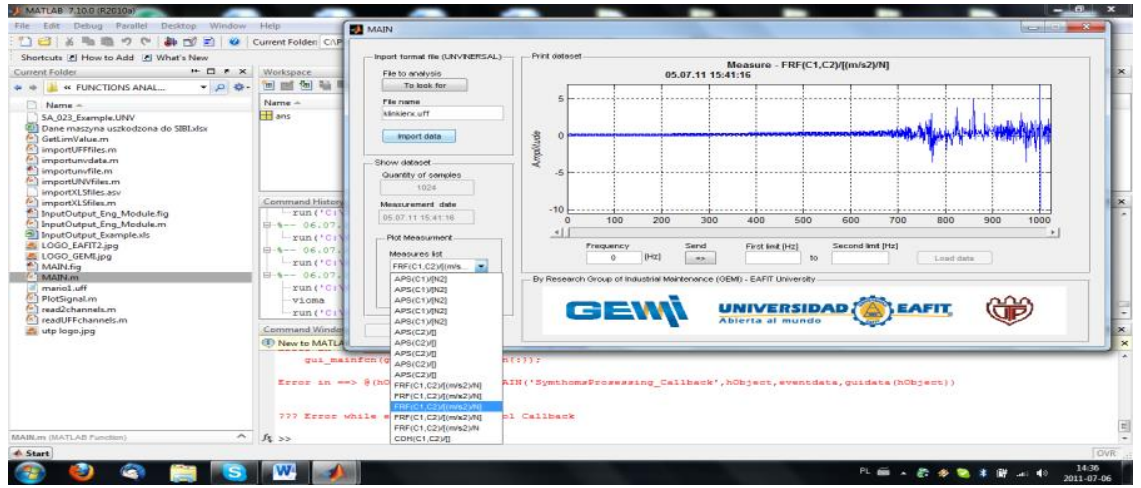

Fig. 5. The main screen of the FUNCTIONS ANALYSIS program.

The range of functions that we mark in the program for counting the surface area we are interested in is graphically marked by red. In the example drawing below, all the functions have been marked and the area of functions in the full frequency range was calculated - Fig. 6.

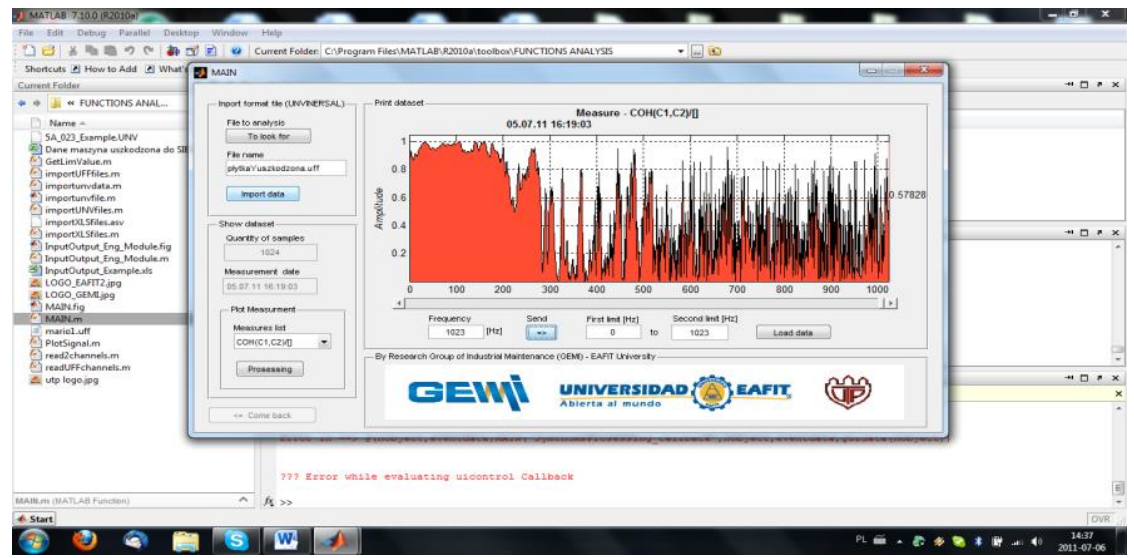

Fig. 6. Graph showing the selected function areas. 


\section{Results}

During the tests, the vibration signal transition function was generated by the structure (FRF function) and stabilization diagrams with the applied vibration frequencies for each element.

The following are the averaged results of the tests in the form of stabilization diagrams, which were prepared for 10 measurements (10 extortions and 10 responses) for the good components and damaged wall elements.
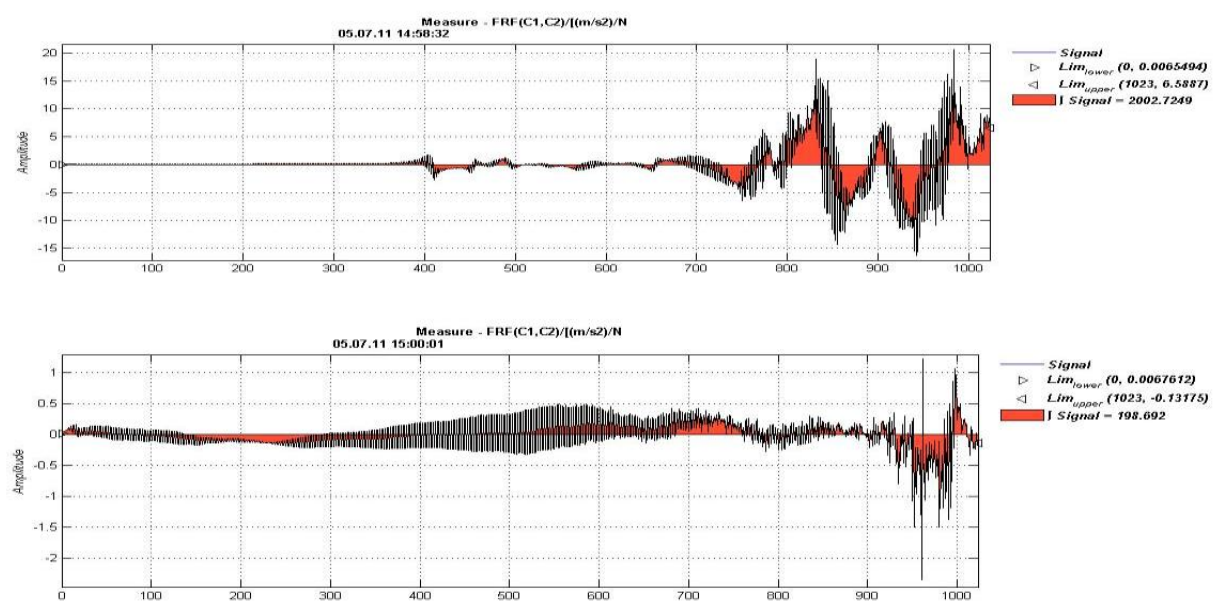

Fig.7. Area of the FRF function for solid and damaged brick in the $\mathrm{X}$ axis.
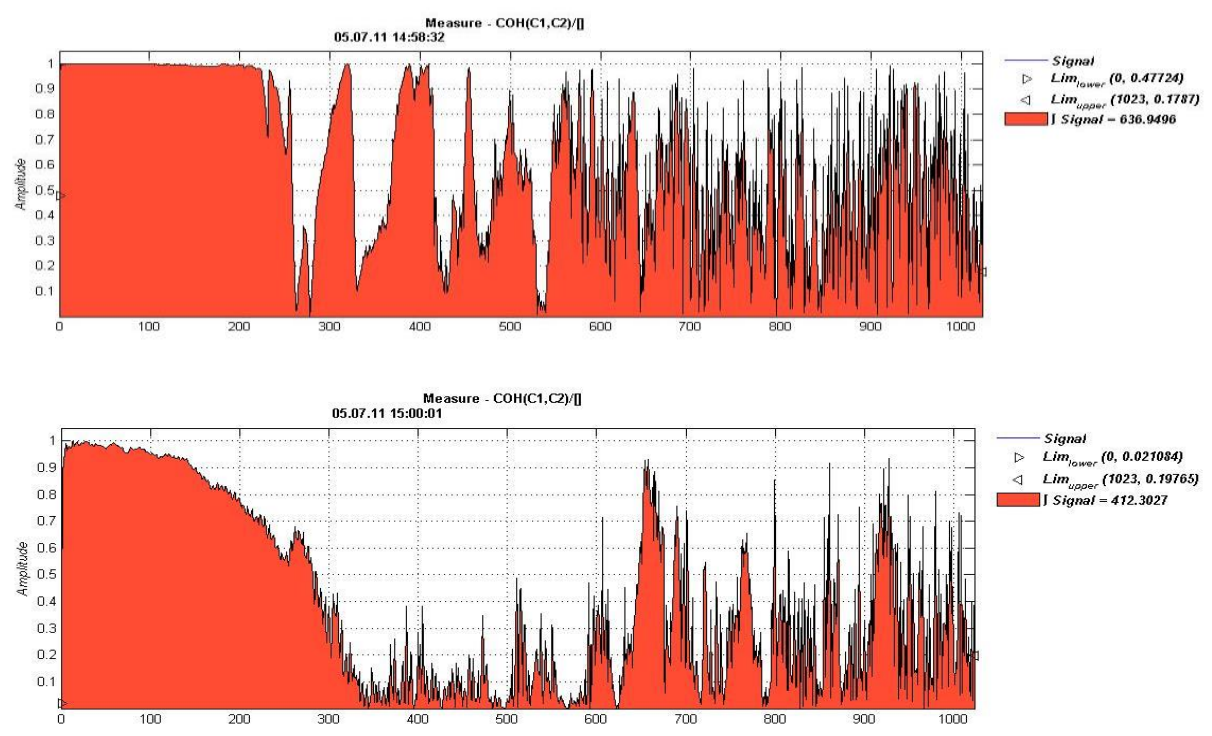

Fig.8. Coherence function surface fields for full and damaged brick in the $\mathrm{X}$ axis 

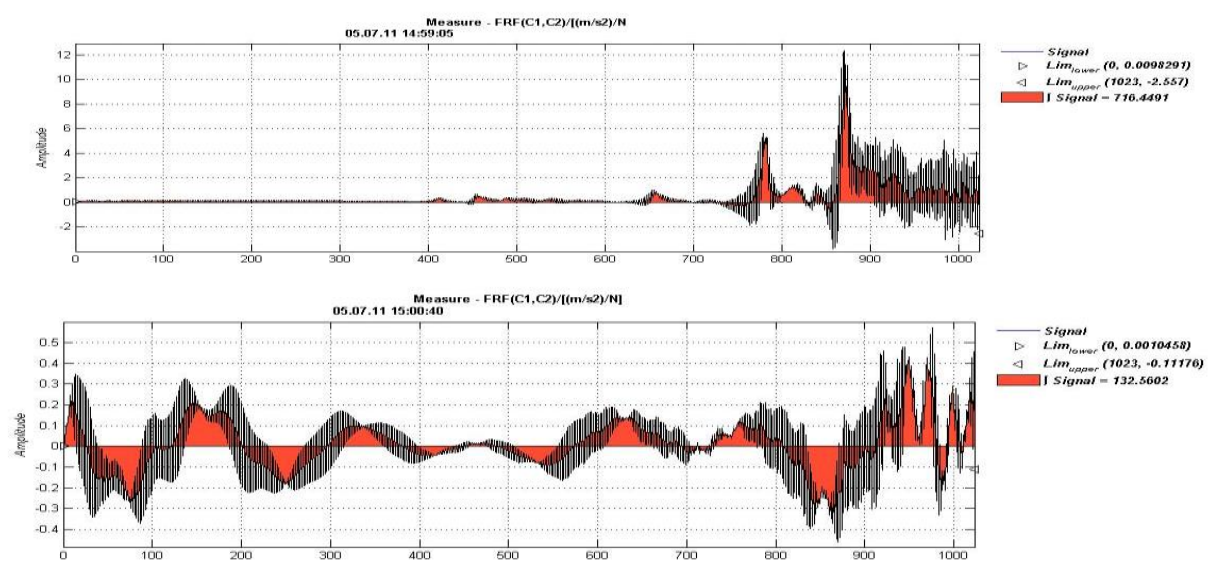

Fig. 9. Area of the FRF function for solid and damaged brick in the $\mathrm{Y}$ axis.
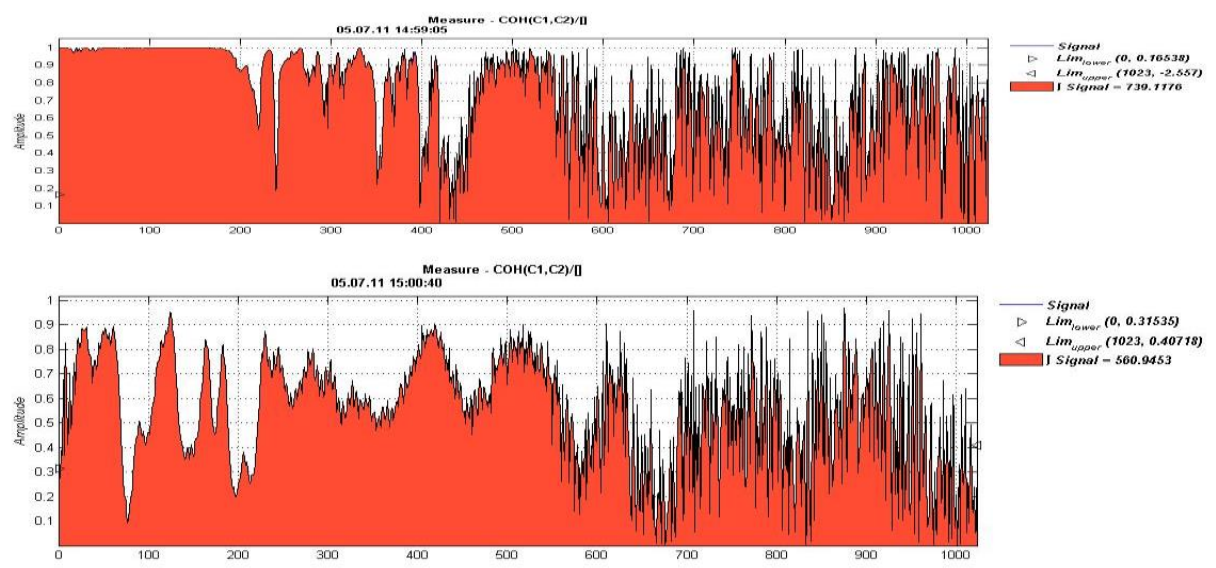

Fig. 10. Coherence function surface fields for full and damaged brick in the $\mathrm{Y}$ axis.
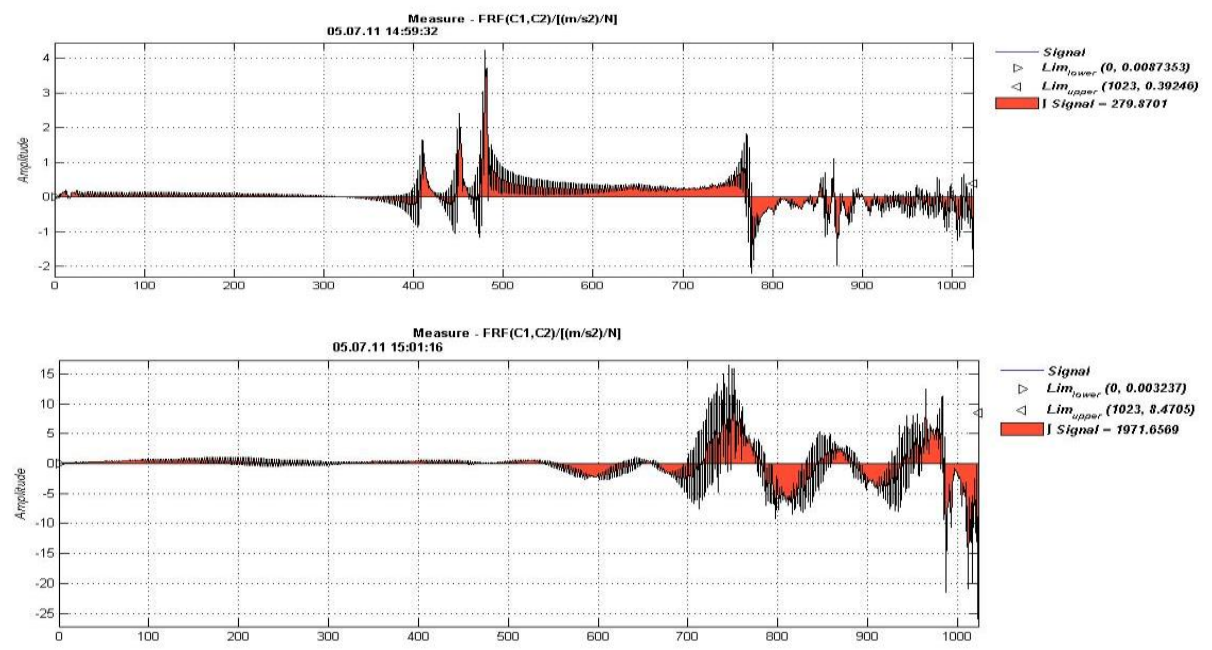

Fig. 11. Area of the FRF function for solid and damaged brick in the $\mathrm{Z}$ axis. 

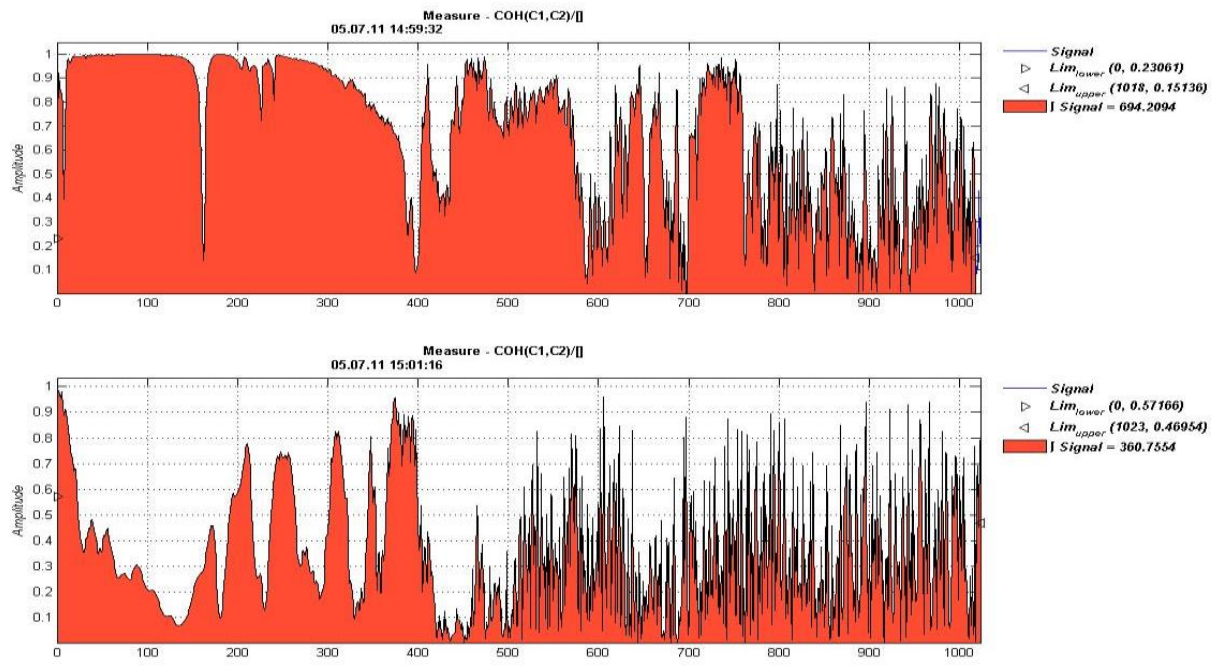

Fig.12. Coherence function surface fields for full and damaged brick in the $\mathrm{Z}$ axis.

\section{Summary}

The publication describes a thoroughly complex process of obtaining measurement data, which can be considered as a unified system of exploitation of test results and their validation and generation of significant values of natural frequency

The presented research results indicate that it is possible to distinguish between material properties, which affects the ability to distinguish their strength properties. The tests also confirmed the suitability of measuring equipment for tests using exploitative modal analysis performed on real structural elements.

\section{References}

1. B. Żółtowski, M. Żółtowski, Vibration signals in mechanical engineering and construction (ITE-PIB 2015)

2. B. Żółtowski, C. Cempel, Engineering of diagnostics machines (PTDT, ITE - PIB 2004)

3. M. Żółtowski, Investigations of harbour brick structures by using operational modal analysis. Polish Maritime Research No 1, (2014)

4. M. Żółtowski, B. Żółtowski, Vibrations signal to the description of structural damage of dynamic the technical systems (XIII International Technical Systems Degradation Conference 2015)

5. M. Żółtowski, Opis drganiowy konstrukcji budowlanych. Logistyka nr.6/2014 (2014).

6. M. Żółtowski, Investigations of harbour brick structures by using operational modal analysis. Polish Maritime Research No. 1/(81) vol.21 (2014)

7. M. Żółtowski, M. Liss, The use of modal analysis in the evaluation of welded steel structures. Studies and Proceedings of Polish Association for Knowledge Management Vol.79 (2016)

8. M. Żółtowski, M. Liss, Zastosowanie eksperymentalnej analizy modalnej $w$ ocenie zmian sztywności prostego elementu konstrukcyjnego. Studies and Proceedings of Polish Association for Knowledge Management Vol. 80 (2016)

9. M. Żółtowski, R.M. Martinod, Technical Condition Assessment of Masonry Structural Components using Frequency Response Function (FRF). Masonry International Journal of the International Masonry Society Vol.29,No.1 (2016) 
10. M. Żółtowski, R.M. Martinod, Quality identification methodology applied to wallelements based on modal analysis. Civil Engineering the Athens Institute for Education and Research, Emerald, Athens (2015) 